\title{
Smart Aquarium Based On Internet of Things
}

\author{
R. Hafid Hardyanto ${ }^{1}$ \\ Teknik Informatika, Universitas PGRI Yogyakarta, Indonesia \\ hafid@upy.ac.id \\ Prahenusa Wahyu Ciptadi² \\ Teknik Informatika, Universitas PGRI Yogyakarta, Indonesia \\ nusa@upy.ac.id \\ Andik Asmara $^{3}$ \\ Pendidikan Teknik Mekatronika Universitas Negeri Yogyakarta, Indonesia \\ andikasmara@uny.ac.id
}

\begin{abstract}
IoT technology has been widely applied in everyday life. IoT technology has been applied to smart home, smart city, and several supporting applications implemented by IoT technology. IoT technology can also be applied in hobby of keeping fish.

The aquarium system that is sold in the market today is an ordinary aquarium. The aquarium system on the market today is already interesting, with a collection of plants and fish in the aquarium, but the problems that occur if the aquarium is stored in the house will be less to the needs of sunlight. Sometimes the lights that have a diaquarium are not adapted to the needs of plants or fish in the aquarium. Another problem is the provision of fish feed that is still manual. Sometimes aquarium owners must provide fish feed manually at least once a day. This is very troublesome if the owner of the aquarium has a very high activity, so the risk of forgetting to feed fish is very high.

To overcome the problems mentioned above, it is necessary to have an aquarium system that is eyecatching and completely automated, both in terms of lighting and aspects of fish feeding. A smart aquarium system that can accommodate aquarium hobbyists with all the activities owned by aquarium owners. In this paper, we designed a new smart aquarium system using IoT devices
\end{abstract}

Keywords: IoT; smart aquarium; keeping fish

\section{Introduction}

An aquarium is a vivarium usually placed in a place with transparent sides (from glass or high-strength plastic), in which animals and aquatic plants (usually fish, but can also be found invertebrates, amphibians, marine mammals and reptiles) are accommodated, and used for public display. Based on Maharani et.al (2016), Aquaponik is a modern farming system by combining planted farming, which produces plants and fish. The way aquaponics works is to use nutrient-rich water as a provider of food and organic nutrients to help plant growth, whereas plants cleanse, filter, and recycle the water environment, thus creating a symbiotic relationship between plants and fish. Burange and Misalkar (2015) say that IoT technology is one of the technologies developed to make it easier for humans to monitor, control an internet-based system. Internet of Things (IoT) is a structure in which objects, provided with exclusive identity and the ability to move data over a network without requiring two directions both human to human and human to computer interaction. With this technology, it is expected to help monitor the plants and fish they cultivate. The application of IoT technology in agriculture is expected to be able to increase agricultural efficiency in the modern era. 


\section{Literatur review}

The research by M.Mahendran, G. Sivakannu, Sriraman Balaji describe that Implementation Of Smart Farm Monitoring Using IoT improves the operational efficiency and system application flexibility by using the wireless sensor network instead of the traditional wired network and at the same time reduces the manpower cost. The practical application approved that the gateway run fine in the green monitoring system, the environment data of the greenhouse can transfer reliably and the control instruction sent timely. This design realizes remote intelligent monitoring and control of greenhouse and is helpful to farms to scientific and rational planting crops.

Stephen C. Kerns Joong-Lyul Le presented an automated aeroponics system using IoT devices. The system designed and implemented an automated aeroponics system to collect each sensor's data in the system. System used a Raspberry Pi Zero and designed the system to measure and control the environmental factors necessary to reach our optimal agricultural needs. We implemented a mobile application, service platform, and a control module on an IoT device that the user can monitor and control the Aeroponics system remotely. Our proposed system is expected to be a promising application to help farmers increase the production of organic crops in a smart farming system.

In the study conducted by Vaibhavraj S. Roham, Abhijeet S. Patil, Prasad R. Rupnar, Ganesh A. Pawar show that In farming Temperature, Humidity and $\mathrm{CO} 2$ are the most essential parameters. The growth of crops is mainly depending on these three parameters. Currently farmers don't have any system which will show real-time levels of these parameters. Even farmer don't know when humidity is increased or CO2 level increased in his green house, because of it crop production gets affected. The proposed system is going to monitor these changes periodically and take an action automatically or pretend the required action to the farmer. Systemwill have a provision to visualize the graphical representation of all the streaming data from the green house. Later on farmer can operate the devices from remote location by using its smart phone, Vaibhavraj (2015).

\section{Results and Discussion}

Based on field surveys, Aquascape is interesting because we not only raise fish but also maintain all the components in the aquarium (Charly, a seller of ornamental fish in pingit). The aquarium system on the market today is already interesting, with a collection of plants and fish in the aquarium, but the problems that occur if the aquarium is stored in the house will be less to the needs of sunlight. Sometimes the lights that have a diaquarium are not adapted to the needs of plants or fish in the aquarium. Another problem is the provision of fish feed that is still manual. Sometimes aquarium owners must provide fish feed manually at least once a day. This is very troublesome if the owner of the aquarium has a very high activity, so the risk of forgetting to feed fish is very high.

To overcome the problems mentioned above, it is necessary to have an aquarium system that is eye-catching and completely automated, both in terms of lighting and aspects of fish feeding. A smart aquarium system that can accommodate aquarium hobbyists with all the activities owned by aquarium owners. This smart aquarium is equipped with automatic lighting, automatic feeders, and automatic water content measurement. 
Currently the existing aquarium system is not yet equipped with an automatic lighting system, automatic feeder, and automatic moisture content measurements that can be monitored via a smartphone. This new smart aquarium system will complement the aquarium market, and is expected to accommodate aquarium hobbyists with high activity. On this basis, the researchers are interested in researching smart aquariums in accordance with the current era of automation, namely an IoT-based smart aquarium.

\section{Smart Aquarium Architecture}

The architecture of Smart aquarium consists of hardware and software. Hardware consists of a control system that uses a microcontroller at mega 328, and supporting sensors as input data to the microcontroller. The sensor used in this article is a light sensor, as a detector of light received by plants, humidity sensors, and water level sensors that are used to monitor water level. Software consists of a web-based interface that allows users to monitor the aquaponic system. Figure.1 show the overall architecture diagram of the Smart aquarium.

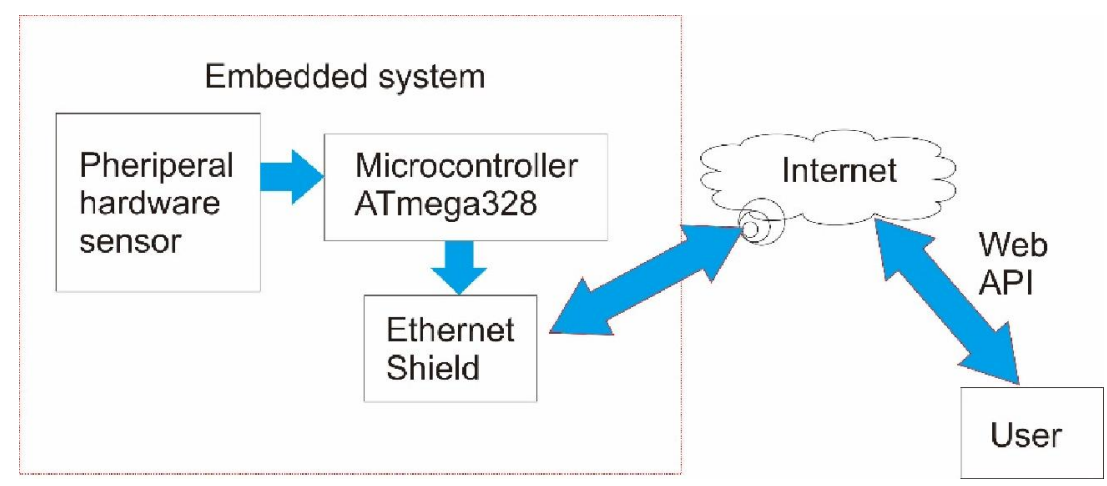

Figure 1. Architecture diagram of Smart Aquaponics

\section{Circuit Design}

In the schematic design described the arrangement of components and pathways used to create a Smart Aquaponics system. Schematic design of Smart aquarium prototype is shown in Figure 2. 


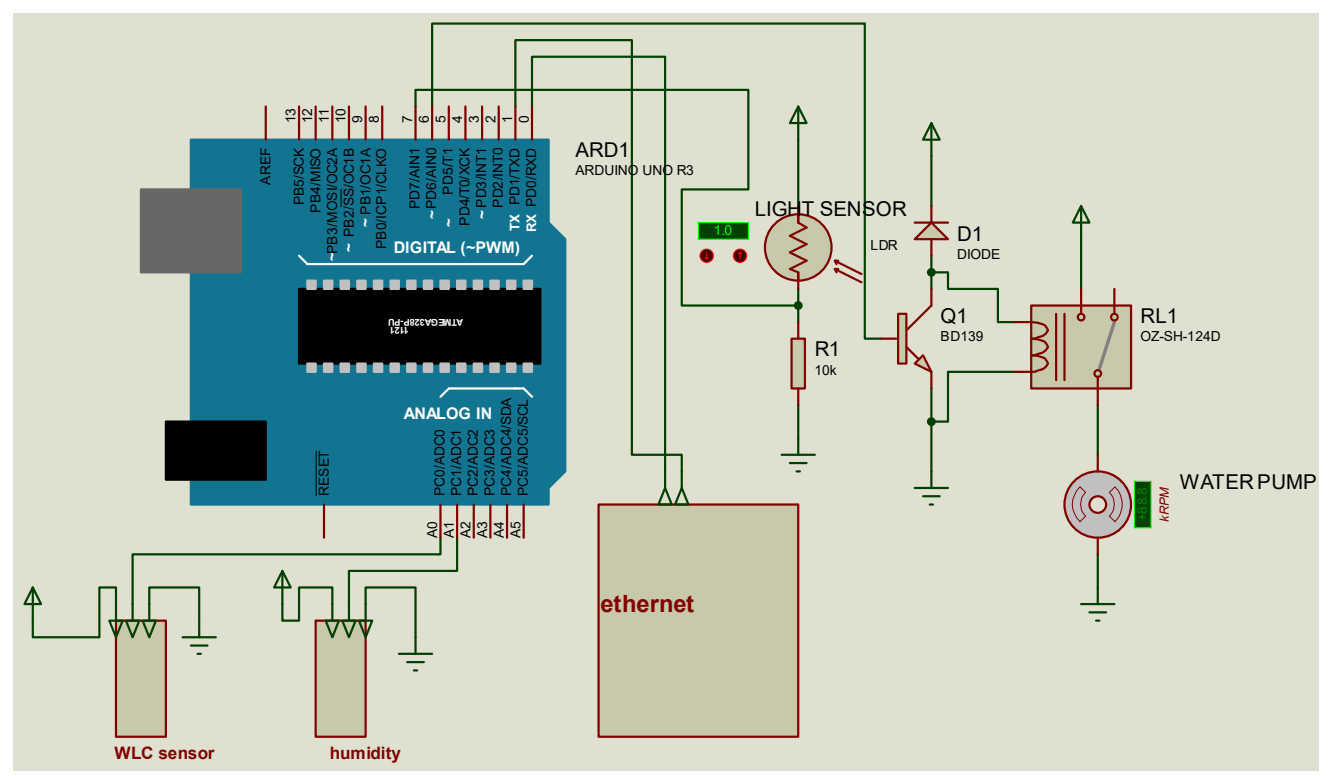

Figure 2. Schematic design of Smart Aquaponics

The Smart Aquaponic design above consists of a microcontroller at mega 328, water level sensors, light sensors and humidity sensors. The sensor functions as input data that is processed in the microcontroller which is then sent to the user via the internet network.

\section{Interface Design}

The interface design between the system and the user is shown in figure 3 below. The web-based interface consists of information on lighting, humidity, and water level on smart aquaponic. This interface functions as a monitor between the smart aquaponic system and the user.

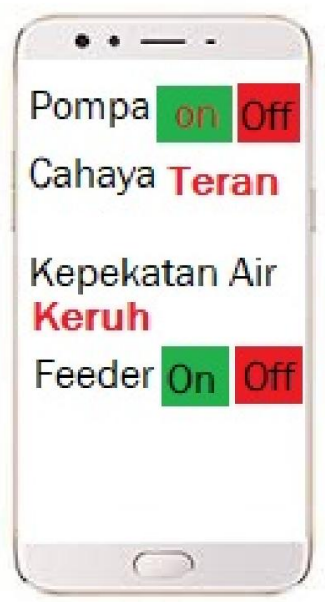

Figure 3. Interface design of Smart Aquaponics

From the picture above the user can monitor humidity, water level, and lighting of the system. Users can also turn on and turn off the water pump on the Smart aquarium

\section{Work Principle}

The working principle of the Smart aquaponics system shown in Figure 4. In Figure 4 it is explained that the smart aquaponics is comprised of 2 parts, hardware and software. 
Hardware consists of sensor as input to the microcontroller which is placed in the aquaponic system, and ATMEGA 328 control as the main control center. ATMEGA 328 microcontroller is equipped with ESP8266 module for communication with users using the internet. Users can obtain information on water level control, lighting, and humidity on aquaponics systems online.

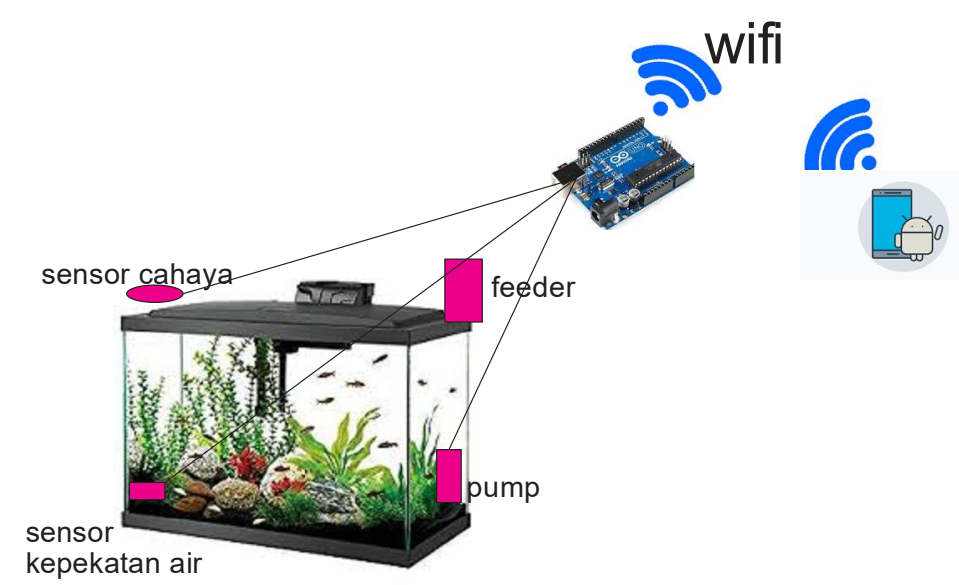

Figure 4. Overall principle of smart aquarium system.

The system is monitored by humidity sensors, light sensors, water level sensors. Solar panels function as a system power source. The system can be observed by users through the internet network. Users can also turn on and turn off the water pump via a web-based interface.

\section{Conclusion}

IoT technology can be developed in any field. One of them is the development of IoT technology in hobby keeping fish. Smart aquarium is a concept of hobby by combining aquarium with IoT System. Smart aquarium is an emerging and real concept for the world of modern hobby keeping fish that combines aquaponics with IoT technology.

\section{References}

Burange, A.W, \& Misalkar, H.D. (2015). Review of Internet of Things in Development of Smart Cities with Data Management \& Privacy. International Conference on Advances in Computer Engineering and Application (ICACEA), IEEE.

Maharani, N.A., \& Sari, P N. (2016). Penerapan Aquaponic Sebagai Teknologi Tepat Guna Pengolahan Limbah Cair Kolam Ikan Di Dusun Kergan, Tirtomulyo, Kretek, Bantul, Yogyakarta. Indonesian Journal of Community Engagement, 1(2), 172-183.

Mahendran., Sivakannu, G., \& Sriraman, B. (2017). Implementation of Smart Farm Monitoring Using IoT. International Journal of Current Engineering And Scientific Research (IJCESR) ISSN (PRINT): 2393-8374, (ONLINE): 2394-0697, 4(6), 21-27. 
Stephen C. Kerns, Joong-Lyul Lee. (2017). Automated Aeroponics System Using IoT for Smart Farming. 8th International Scientific Forum, ISF 2017, UNCP, USA, Proceedings. 104-111.

Vaibhavraj S. R., Ganesh A. P., \& Abhijeet S.P., \& Prasad R. R. (2015). Smart Farm using Wireless Sensor Network. International Journal of Computer Applications (0975 8887), National Conference on Advances in Computing (NCAC 2015).

(2018). https://yogyakarta.bps.go.id/dynamictable/2018/02/01/107/luaspenggunaan-lahan-pertanian-dan-bukan-pertanian-di-d-i-yogyakarta.html 